\title{
Penanaman Karakter Anak Usia Dini melalui Lagu Anak-anak Daerah Lampung
}

\author{
Dharlinda Suri ${ }^{\circledR}$ \\ Pendidikan Guru Pendidikan Anak Usia Dini, Sekolah Tinggi Keguruan dan Ilmu \\ Pendidikan PGRI Bandar Lampung, Indonesia(1) \\ DOI: $\underline{10.31004 / o b s e s i . v 6 i 2.1659}$
}

\begin{abstract}
Abstrak
Saat ini sangat sedikit sekali anak-anak yang bisa menyanyikan lagu-lagu anak daerah Lampung. Anak-anak cenderung menyanyikan lagu-lagu yang sedang populer salah satunya lagu soundtrex film. Penelitian ini bertujuan untuk menanamkan nilai-nilai karkater pada anak usia dini melalui lagu anak-anak daerah lampung. Metode yang digunakan dalam penelitian ini adalah metode deskriptif kualitatif. Adapun Teknik analisis data dalam penelitian yaitu dengan menggunakan teknik deskriptif dengan membuat gambaran yang dilakukan dengan cara pengumpulan data, reduksi data, penyajian data, dan kesimpulan. Berdasarkan hasil penelitian serta pembahasan dapat disimpulkan bahwa nilai-nilai Pendidikan karakter pada lagu anak-anak daerah lampung yang berjudul cinta Tuhan segenap ciptaannya, Kutak mainan, sanak santun, dan sanak teghtib, seperti: religius, disiplin, mandiri, tanggungjawab, sopan santun, hormat, jujur, dan bijaksana. Melalui lagu-lagu anak daerah anak mampu mengenal, mengetahui, dan mempunyai rasa cinta daerah serta tanah air.
\end{abstract}

Kata Kunci: pendidikan karakter; budaya local; pendidikan anak usia dini

\begin{abstract}
This study aims to instill character values in early childhood through Lampung children's songs. The method used in this study is a qualitative descriptive method. The data analysis technique in this research is by using descriptive techniques by making a picture which is done by means of data collection, data reduction, data presentation, and conclusions. Based on the results of the research and discussion, it can be concluded that the values of character education in the Lampung regional children's song entitled Love of God for all his creations, Kutak toys, polite relatives, and strong relatives, such as: religious, disciplined, independent, responsible, polite, respectful, honest and wise. Through local children's songs, children are able to recognize, know, and have a sense of love for the region and the homeland.
\end{abstract}

Keywords: character education; local culture; early childhood education

Copyright (c) 2021 Dharlinda Suri

$\triangle$ Corresponding author :

Email Address : dharlindasurii@gmail.com (Lampung, Indonesia)

Received 17 February 2021, Accepted 30 July 2021, Published 1 August 2021 


\section{PENDAHULUAN}

Pendidikan moral sebaiknya memang ditanamkan sejak dini karena dapat membentuk karakter bangsa menjadi lebih baik. Dapat dipahami bahwa, pendidikan moral dapat dimulai dari hal-hal di sekitar tempat tinggal anak-anak usia dini. Salah satunya dengan mempelajari dan memahami makna lagu daerah yang sarat akan pesan moral kehidupan (Alfianti, 2021; Rosmiati, 2014). Lebih lanjut dikemukakan bahwa dengan perkembangan teknologi yang semakin pesat, sesungguhnya suatu lagu dapat dengan mudah diperdengarkan di mana pun dan dalam waktu kapan pun, tidak terkecuali lagu daerah (Anwar, 2021; Rantina et al., 2019; Wijiasih et al., 2020). Dapat dipahami bahwa, hal semacam ini terjadi karena adanya peran media. Dengan adanya media, pesan dari sebuah lagu dapat tersampaikan dengan tepat dan efisien. Media ada beberapa macam, di antaranya media visual, media audio, dan media audio visual (Ayuni \& Setiawati, 2019). Media yang paling tepat dan efisien untuk memperkenalkan suatu lagu adalah media audio (suara), karena media ini berhubungan langsung dengan suara (sound) dan indra pendengaran manusia. Media audio cukup memudahkan seseorang dalam mengapresiasi suatu lagu (Hasanah, 2018; Purwanto, 2019; Restian \& Mukhlishina, 2017).

Lagu daerah merupakan salah satu warisan kekayaan budaya Indonesia dengan bentuk ungkapan perasaan, pikiran dan khas masing-masing dari suatu daerah tertentu (Ardiansyah \& Amalia, 2017; Purnomo et al., 2016). Dalam kehidupan, lagu daerah memiliki makna yang amat luhur. Terlebih untuk membentuk karakter anak menjadi pribadi yang baik di masa depan. Lagu anak-anak daerah Lampung merupakan salah satu bentuk ungkapan perasaan dan pikiran anak-anak daerah Lampung memiliki makna yang amat luhur. Terlebih untuk membentuk karakter anak menjadi pribadi masyarakat Lampung yang baik di masa depan. Selain itu, lagu daerah digunakan untuk menanamkan philosophi masyarakat Lampung yang terkenal dengan istilah Piil Pesenggiri. Piil Pesenggiri adalah pedoman hidup dalam bersikap dan berprilaku dalam masyarakat adat Lampung di berbagai aktivitas hidupnya. Piil Pesenggiri memiliki makna yang mendalam bagi masyarakat Lampung yaitu sebagai pedoman hidup. Ini bermakna setiap gerak dan langkah kehidupan masyarakat Lampung dalam kehidupan sehari-hari dilandasi dengan kebersihan jiwa.

Saat ini sangat sedikit sekali anak-anak yang bisa menyanyikan lagu-lagu anak daerah Lampung, mereka cenderung menyanyikan lagu-lagu yang sedang populer saat ini seperti lagu soundtrex ganteng-ganteng serigala, soundtrex anak jalanan yang judulnya cinta gila, aku pasti bisa sountrex dari tujuh manusia harimau dan beberapa lagu-lagu yang sekarang selalu di putar setiap hari di Televisi. Hal ini disebabkan anak-anak saat ini hidup di zaman globalisasi, teknologi informasi semakin canggih. Zaman yang serba cepat yang menumbuhkan budaya instan, budaya yang besar pengaruhnya terhadap perkembangan peradaban yang berdampak pada perkembangan sosial dan emosional masyarakatnya. Budaya ini merambah pada semua aspek, baik itu politik, ekonomi, sosial maupun budaya itu sendiri. Sebagai bangsa yang memiliki sangat banyak kekayaan dan keragaman, diantaranya kekayaan dan keragaman budaya lokal akan terisolasi dengan sendirinya manakala kita tidak sejak dini menanamkan tekad kuat untuk memperkuat dan melestarikan budaya lokal kita yang kaya akan nilai-nilai luhur. Kekhawatiran terhadap dampak pendidikan global yang entah disadari atau tidak terdapat di dalamnya lambat laun akan menggeser posisi dan daya tawar budaya lokal. Senada dengan Ardiansyah \& Amalia (2017) bahwa dengan berkembangnnya zaman semakin banyak lagu yang modern dan asing ke Indonesia, sehingga masyarakat tidak menyadari pentingnya budaya yang ada di Indonesia dan anak-anak kurang mengenal lagu daerahnya sendiri.

Selanjutnya, kehadiran musik dalam kehidupan manusia merupakan dua hal yang saling bersinergi (Muliati \& Sari, 2018). Dapat dipahami bahwa, musik dapat digunakan sebagai media pembentukan karakter ataupun aspek perkembangan pada anak usia dini (Kusumawati, 2015; Prahesti et al., 2019; Rantina et al., 2019). Lebih lanjut, pembentukan karakter dibutuhkan untuk menanamkan pendidikan, kepribadian, dan moral kepada anak usia dini. Sebagai contoh, lirik sebuah lagu dapat mempengaruhi kejiwaan anak-anak (Basma 
\& Melga, 2020; Indriana et al., 2019; Widjanarko, 2019). Salah satunya dengan menciptakan lagu anak yang bertema nilai-nilai kebaikan yang dapat membangun kepribadian atau karakter pada anak (Ardipal, 2021; Sholeh, 2018; Tarmizi, 2017). Dapat dipahami bahwa, pendidikan anak usia dini memiliki peran yang besar dalam membangun dan membentuk karakter jangka panjang pada anak. Selanjutnya, orangtua memegang keberhasilan dan kesuksesan mendidik pada masa kecil (Anwar, 2021; Zulaikhah, 2019). Lebih lanjut, perhatian dan kasih sayang menjadi kunci sukses keberhasilan dalam membentuk karakater pendidikan yang berkualitas pada anak.

Pendidikan Anak Usia Dini sebagai salah satu kunci penentu masa depan bangsa memegang peranan penting dalam menguatkan nilai-nilai budaya lokal. Berdasarkan peraturan Pemda Provinsi Lampung diatas, maka salah satu upaya yang perlu dilakukan adalah pendidik anak usia dini di lembaga pendidikan provinsi Lampung, perlu untuk menanamkan nilai-nilai karakter masyarakat Lampung sejak anak usia dini melalui media lagu-lagu anak daerah Lampung. Dengan memperdengarkan lagu-lagu daerah Lampung kepada anak sejak dini diharapkan ada hasil positif terkait dengan nilai-nilai karakter yang dapat diambil dan ditanamkan pada anak melalui media lagu-lagu daerah Lampung tersebut.

Penelitian tentang lagu anak-anak telah dilakukan oleh beberapa peneliti. Penelitian yang telah dilakukan oleh Putra \& Noordiana, (2020) tentang membangun karakter siswa melalui lagu sisemut karya pambuko di SMPN 2 Mojo Kabupaten Kediri menunjukan bahwa penggunaan lagu efektif dalam meningkatkan karkater siswa. Selanjutnya penelitian yang telah dilakukan oleh Rukiyati Sugiyo \& L. Andriani Purwastuti, (2017) tentang model Pendidikan karakter berbasis kearifan local pada sekolah dasar di bantul yogyakarta menunjukan bahwa kearifan local efektif dalam menanamkan nilai karkater kepada siswa. Penelitian yang telah dilakukan oleh Seriadi, (2019) mengenai pembentukan karkater unggul dan nasionalis pada anak usia dini melalui sekar rare menunjukan bahwa lagu anakanak dapat menumbuhkan rasa cinta tanah air. Berikutnya, penelitian yang telah dilakukan oleh Mahmudi et al., (2020) tentang analisis nilai karakter dalam lagu anak karya A.T Mahmud meunjukanbahwa nilai religius, rasa ingin tahu, menghargai prestasi, kerja keras, jujur, disiplin, komunikatif, kreatif dan efektif digunakan dalam pembelajaran. Selanjutnya, penelitian yang telah dilakukan oleh Laali, (2018) pembentukan karakter anak melalui lagu kokonua menunjukan bahwa lagu kokonua terdapat nilai-nilai karakter yang dibentuk pada anak usia 5 tahun di pulau Kabalutan yaitu mandiri, bertanggung jawab, pekerja keras, jujur, saling menyayangi, kebersamaan/solidaritas, riang gembira, sabar, tangguh dan bersyukur.

Berdasarkan pemaparan di atas, peneliti perlu melakukan kajian secara ilmiah mengenai penanaman karakter anak usia dini melalui lagu anak-anak daerah lampung. Tujuan dari penelitian ini adalah untuk menanamkan nilai-nilai karkater pada anak usia dini melalui lagu anak-anak daerah lampung. Keterbaruan penelitian ini adalah menjelaskan penanaman nilai karakter pada anak usia dini pada lagu daerah yang ada di Lampung, seperi judul lagu: Cinta Tuhan Segenap Ciptaannya, Kutak Mainan, Sanak Santun, dan Sanak Teghtib.

\section{METODOLOGI}

Penelitian yang digunakan adalah penelitian kualitatif. Lokasi penelitian di PAUD Kota Bandar Lampung. Subjek penelitian anak dengan jumlah 100 orang. Teknik pengumpulan menggunakan studi pustaka, wawancara, dan observasi. Jenis Pendekatan dari penelitian kualitatif yang digunakan adalah dengan pendekatan deskriptif. Dalam Penelitian ini peneliti berfokus kepada nilai-nilai pendidikan karakter pada lagu anak-anak daerah lampung. Oleh karena itu, metode yang digunakan adalah metode kualitatif. Jenis penelitian ini berusaha untuk mengembangkan konsep, pemahaman, dalam bentuk deskripsi. 


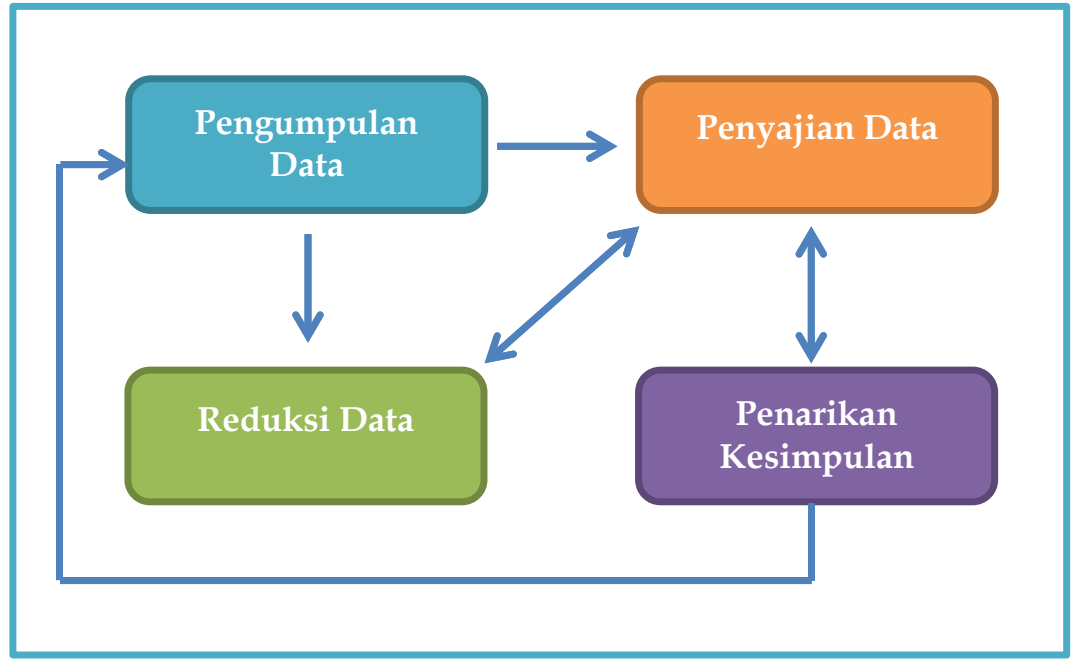

Gambar 1. Analisis Data (Miles \& Huberman, 2005)

Gambar 1 adalah analisis data yang digunakan dalam penelitian dengan menggunakan teknik deskriptif dengan membuat gambaran yang dilakukan dengan cara pengumpulan data, reduksi data, penyajian data, dan kesimpulan.

\section{HASIL DAN PEMBAHASAN}

Berdasarkan hasil analisis yang telah dilakukan oleh peneliti, lagu anak-anak daerah lampung memiliki nilai pendidikan karakter dalam pesan moral setiap lagu anak-anak khususunya di Kota Bandar Lampung. Berikut ini merupakan hasil analisis nilai-nailai karakter yang terdapat dalam lagu anak-anak daerah lampung:

\section{Lagu Cinta Tuhan dan Segenap Ciptaan-Nya}

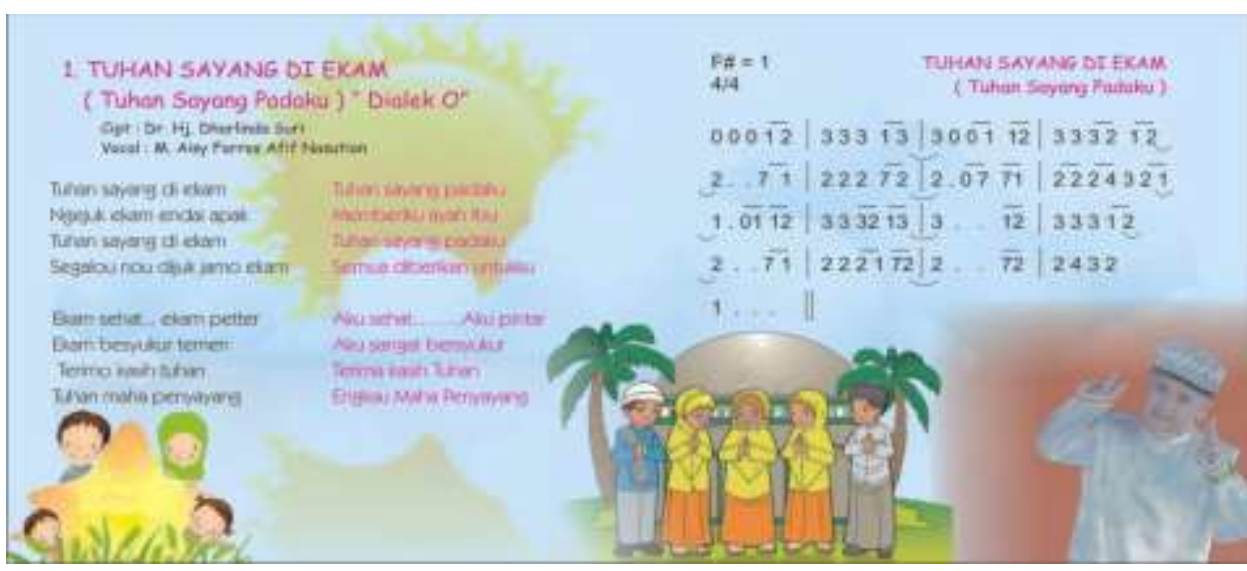

Gambar 2. Lirik lagu cinta tuhan dan segenap ciptaanya

Dalam lagu cinta Tuhan dan segenap ciptaannya tersebut terdapat nilai karakter yang tumbuh untuk anak usia dini adalah Mengenal siapa yang menciptakan dirinya, menciptakan ayah dan ibunya, mensyukuri nikmat yang diberikan Tuhan berupa kesehatan dan kecerdasan, rasa syukur pada Tuhan yang maha pengasih dan maha penyayang. Dapat dipahami baawa nilai karakter religius sangat penting dan fundamen dalam kehidupan manusia. Masyarakat Lampung merupakan masyarakat yang religius, hal ini sangat tercermin dalam falsafah hidup masyarakat Lampung yang tercermin dalam hubungan vertikal dan horizontal berupa keimanan pada Tuhan dan pergaulan sosial pada sesama. Etos dan spirit kelampungan inilah yang harus ditumbuh kembangkan untuk membangun eksistensi 
masyarakat Lampung di era globalisasi. Pada proses pembelajaran, pendidik menjelaskan pada anak bahwa Tuhan yang menciptakan segala yang ada di langit dan di bumi, tuhan pula yang menghidupkan dan mematikan semua makhluk yang ada dibumi. Kita wajib bersyukur kepada Tuhan, dan Pendidik juga menjelaskan bahwa Tuhan maha penyayang. "Tuhan sayang di Ekam" yang artinya adalah Tuhan sayang padaku.

\section{Lagu Kutak Mainan (Kotak Mainan)}

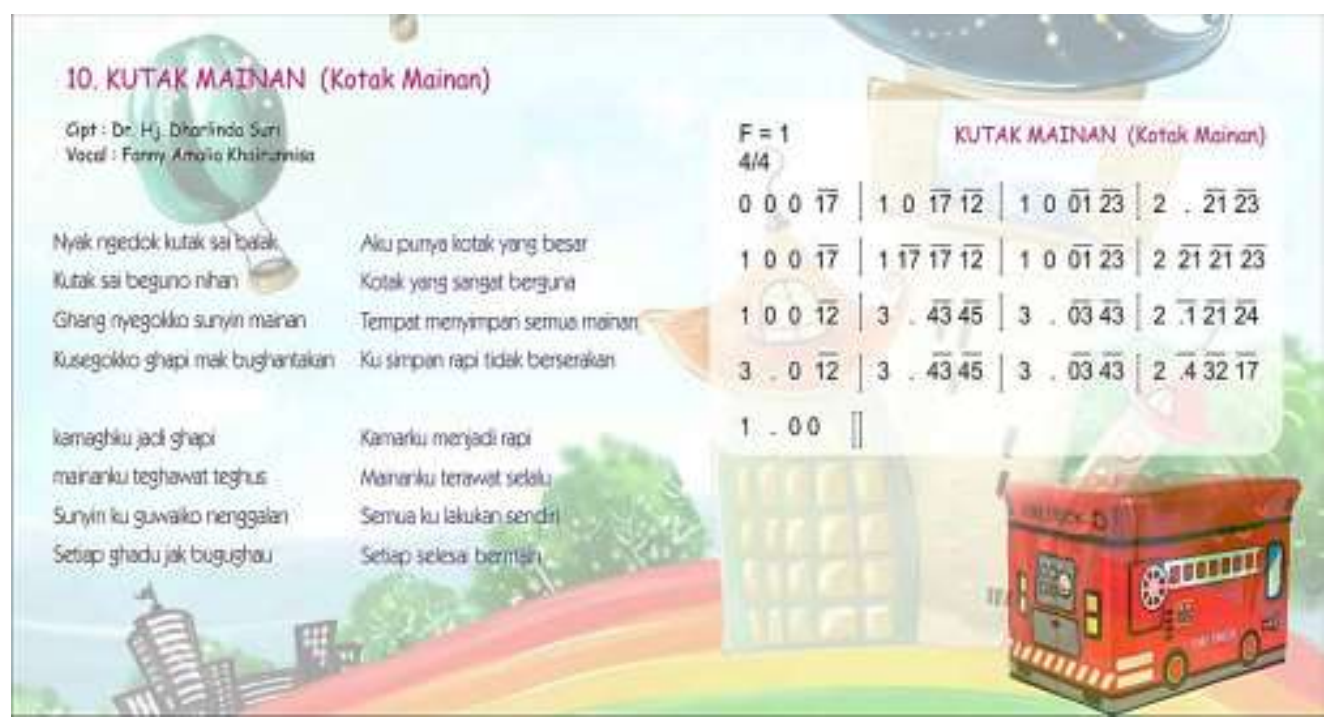

Gambar 3. Lirik lagu Kutak mainan (kotak mainan)

Nilai karakter yang terkandung dalam lagu anak-anak dengan judul Kutak mainan mandiri, disiplin, dan tanggungjawab. Dapat dipahami bahwa nilai karakter yang ditumbuhkan pada anaka pada lagu ini adalah anak dapat Menjaga barang miliknya sendiri, disiplin dan bertanggung jawab terhadap mainan setelah bermain. Mandiri, Disiplin dan tanggung jawab merupakan falsafah hidup masyarakat Lampung yang sangat dijunjung tinggi. Dapat dipahami bahwa dalam kehidupan sehari-hari misalnya mereka mengerjakan sesuatu dengan mandiri, merasa malu jika meminta bantuan pada orang lain, dan segala sesuatunya dikerjakan dengan disiplin dengan penuh tanggung jawab.

\section{Lagu Sanak Santun}

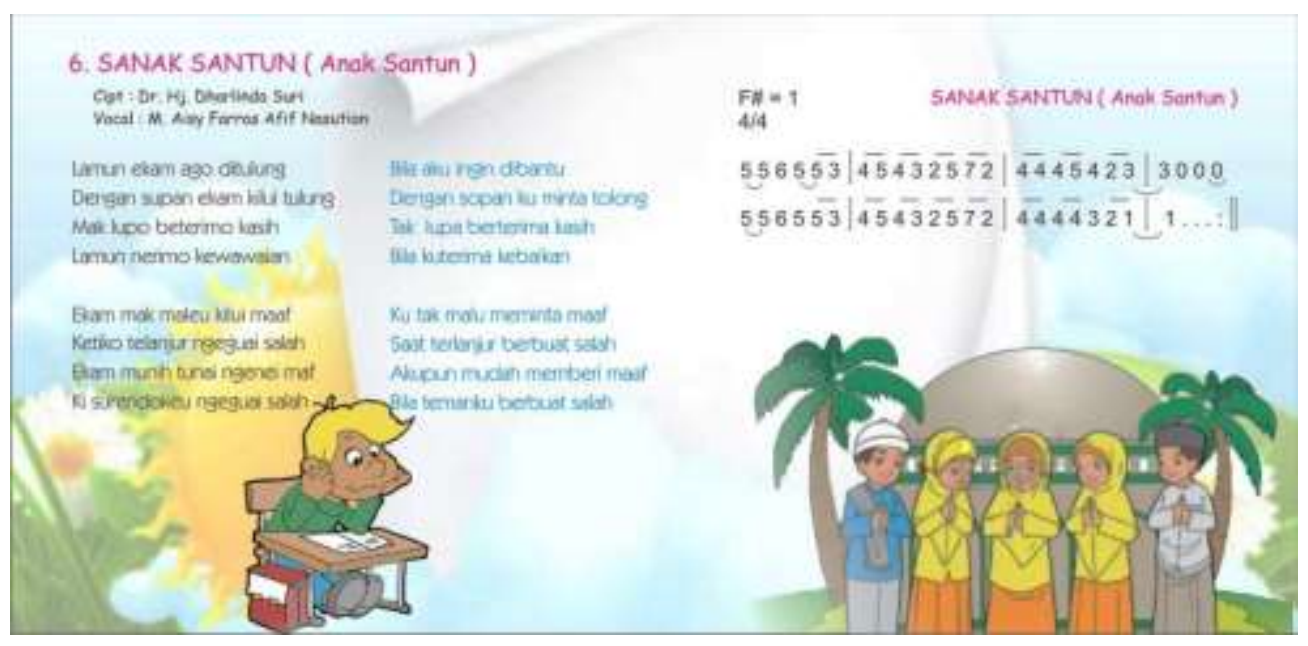

Gambar 4. Lirik lagu sanak santun 
Nilai karakter yang terkandung dalam lagu sanak santun adalah jujur, amanah dan berkata bijak. Dapat dipahami bahwa nilai karakter yang diterpakan pada siswa dalam lagu ini adalah berkata lembut dan jujur dalam menyampaikan informasi yang sebenarnya, mengucapkan terimakasih jika menerima suatu kebajikan, tidak malu mengakui kesalahan jika terlanjur berbuat salah, dan memaafkan teman yang berbuat salah. Dapat dipahami bahwa, lagu "Sanak Santun" (Anak Santun) menandakan bahwa masyarakat Lampung sangat menjunjung tinggi sopan santun dalam pergaulan sehari-hari, jika mereka membutuhkan pertolongan dari orang lain mereka berkata dengan sopan dan dengan kata yang bijak. Lebih lanjut dapat dipahami bahwa masyarakat Lampung selalu konsisten dengan apa yang diperbuatnya, jika mereka merasa bersalah, tanpa malu mereka mengakuinya dan langsung meminta maaf.

\section{Lagu Sanak Teghtib (Anak Tertib)}

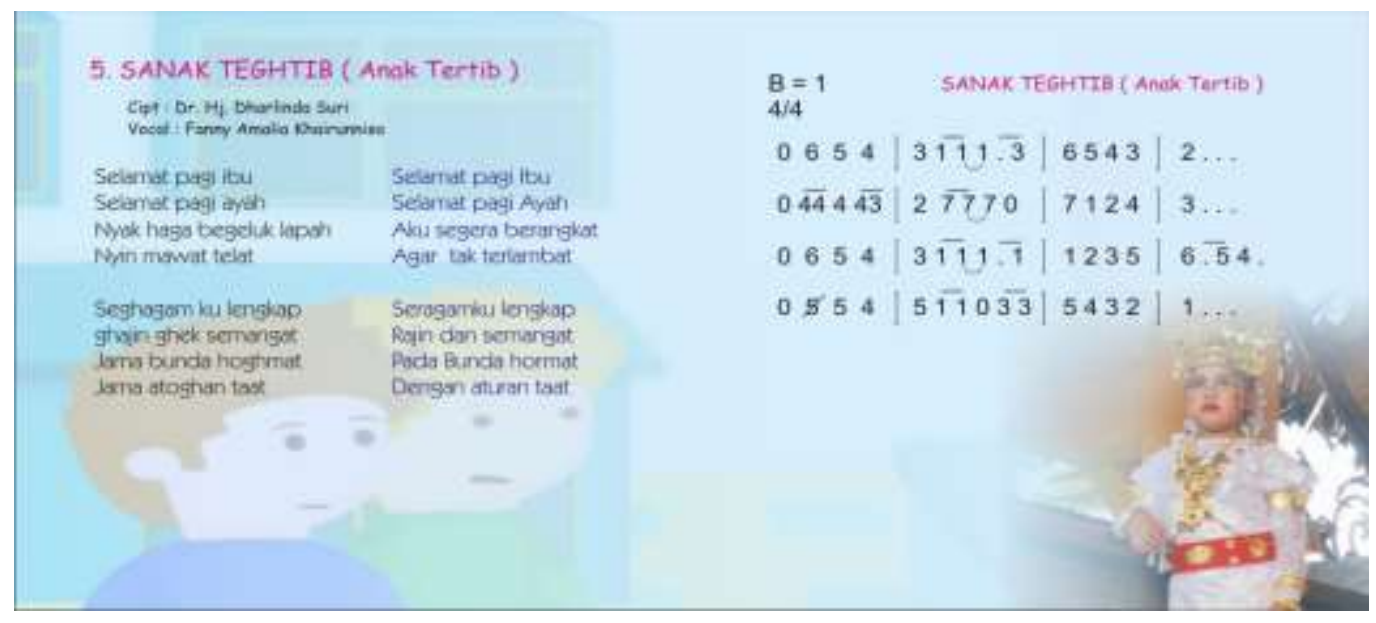

Gambar 5. Lirik lagu sanak teghtib (anak tertib)

Dalam lagu sanak teghtib (anak tertib) terkandung nilai karakter hormat, santun dan pendengar yang baik. Dapat dipahami bahwa hormat, santun dan pendengar yang baik Karakter yang disisipkan dalam lagu ini adalah anak dapat mengucapkan salam dan membalas salam dengan santun, meminta izin dalam melaksanakan sesuatu, dapat menghargai waktu, disiplin dalam berpakaian, menghormati orangtua dan guru dan taat pada aturan di sekolah dan masyarakat. Dapat dipahami bahwa dimanapun masyarakat Lampung bertemu mereka selalu mengucapkan salam "Assalammualaikum warahmatullahi Wabarokatuh" dengan santun. Selain itu juga Salam yang selalu digunakan oleh masyarakat Lampung dalam menyambut tamu-tamu agung adalah "Tabik Puuun" (Salam penghormatan). Menghormati dan selalu mengikuti ajaran yang baik dari kerabat yang lebih tua adalah suatu kewajiban dalam masyarakat Lampung. Dalam lagu ini anak mengucapkan salam kepada orang tuanya dan berpamitan untuk pergi ke sekolah dengan tergesa-gesa karena takut terlambat ke sekolah, rapi dalam berpakaian, taat pada aturan dan hormat pada ayah dan ibu.

\section{Pembahasan}

Hasil analisis di atas menunjukan bahwa setiap lagu anak-anak daerah lampung memiliki nilai-nilai karakter tersendiri. Hal tersebut dapat dilihat dari nilai-nilai karakter yang terkandung disetiap lagunya, nilai karakter pada lagu cinta Tuhan dan segenap ciptaan-Nya adalah karakter religius. Dapat dipahami bahwa nilai religius merupakan nilai karakter yang mengajarkan anak untuk mengenal siapa yang menciptakan dirinya, menciptakan ayah dan ibunya, mensyukuri nikmat yang diberikan Tuhan berupa kesehatan dan kecerdasan, Rasa 
syukur pada Tuhan yang maha pengasih dan maha penyayang. Nilai karakter yang terkandung dalam lagu Kutak mainan adalah mandiri, disiplin, dan tanggungjawab. Dapat dipahami bahwa dalam lagu Kutak maintain anak diajarkan untuk dapat Menjaga barang miliknya sendiri, disiplin dan bertanggung jawab terhadap mainan setelah bermain. Mandiri, disiplin dan tanggung jawab merupakan falsafah hidup masyarakat Lampung yang sangat dijunjung tinggi.

Dalam lagu anak santun terkandung nilai karakter jujur, Amanah, dan berkata bijak. Selanjutnya Karakter yang disisipkan dalam lagu sanak teghtib adalah Anak dapat mengucapkan salam dan membalas salam dengan santun. Meminta izin dalam melaksanakan sesuatu, dapat menghargai waktu, disiplin dalam berpakaian, menghormati orang tua dan guru dan taat pada aturan di sekolah dan masyarakat.

Hasil penelitian di atas sejalan dengan filosofi bahwa Suku Lampung dalam sejarahnya tercatat sebagai salah satu suku yang memiliki peradaban tinggi. Fakta ini bisa tercermin dari kebudayaan yang dimiliki ulun (orang) Lampung. Bukti kongkretnya, suku Lampung memiliki aksara baca tulis yang bernama ka ga nga, bahasa dalam dua dialek Nyow dan Api, Selain itu, salah satu ciri masyarakat Lampung memiliki peradaban juga ditandai adanya filsafat dan falsafah hidup sebagai refleksi atau kesemestaan. Artinya, setiap titi gemati adat atau budaya pasti memiliki dasar filosofi yang mengandung hikmah bagi masyarakat. Masyarakat Lampung mempunyai Piil Pesenggiri sebagai dasar filosofinya dalam kehidupannya. Piil Pesenggiri memiliki arti harga diri, makna prinsip-prinsip yang harus dianut agar seseorang itu memiliki eksistensi atau harga diri.

Menurut Basma \& Melga, (2020) Kesenian lagu daerah merupakan bagian dari karya sastra yang memanfaatkan keindahan untuk memberikan kepuasan terhadap umat manusia. Oleh karenanya lagu daerah menggunakan bahasa sebagai medium utama.Selain mampu menggambarkan kepribadian komunal atau masyarakat setempat, keberadaan lagu daerah mampu menyalakan semangat atau spirit kebersamaan dari komunitas bersangkutan. Tanpa memperhatikan misi maupun fungsi, lagu daerah secara konkrit begitu dekat dengan masyarakat daerah. Menurut Mustopo, (1989) sebagai salah satu unsur kebudayaan, kesenian lagu daerah memiliki corak, ragam, serta ciri khas yang menjadi identitas daerah. Identitas itu menunjukkan sifat-sifat kedaerahan yang perlu dikembangkan untuk kemajuan keseniaan lagu daerahnya.Di dalam lagu daerah selalu berhubungan dengan kehidupan sehari-hari masyarakat suatu komunitas.Seperti untuk keperluan upacara yang bersifat ritual, pekerjaan seperti kegiatan menyambut musim panen, atau juga untuk sarana menyebarkan nilai budaya ataupun sejarah komunitas setempat.

\section{SIMPULAN}

Berdasarkan hasil analisis di atas, dapat disimpulkan bahwa nilai-nilai Pendidikan karakter pada lagu anak-anak daerah lampung yang berjudul cinta tuhan segenap ciptaannya, Kutak mainan, sanak santun, dan sanak teghtib adalah religius, disiplin, mandiri, tanggungjawab, sopan santun, hormat, jujur, dan bijaksana. Melalui lagu anak-anak daerah lampung, anak menjadi semakin mengetahui dan mencitai budayanya sendiri sehingga semakin memupuk nilai-nilai karkater bangsa dalam kehidupan sehari-hari.

\section{UCAPAN TERIMA KASIH}

Peneliti mengucapkan terima kasih kepada pihak yang terlibat dalam penelitian ini salah satunya Pendidikan Anak Usia Dini di Kota Bandar Lampung.

\section{DAFTAR PUSTAKA}

Alfianti, N. (2021). Analisis Pendidikan Karakter Anak Usia Dini Melalui Model Pembelajaran Sentra (Beyond Center and Circle Time). JM2PI: Jurnal Mediakarya Mahasiswa Pendidikan Islam, 1(2), 339-360. https:// doi.org/10.33853/jm2pi.v1i2.121 
Anwar, R. N. (2021). Penanaman Nilai-Nilai Islam Moderat Pada Anak Usia Dini Dalam Keluarga Sebagai Upaya Menangkal Radikalisme. Al Fitrah Journal Of Early $\begin{array}{llll}\text { Childhood Islamic } & \text { Education, } & \text { 155-163. }\end{array}$ https:// doi.org/10.29300/alfitrah.v4i2.3883

Ardiansyah, W., \& Amalia, D. R. (2017). Pembangunan Aplikasi Media Pembelajaran Lagu Daerah Berbasis Teknologi Multimedia. Jurnal ICT: Information Communication \& Technology, 16(2), 48-52. https:// doi.org/10.36054/jict-ikmi.v16i2.22

Ardipal, A. (2021). Pemanfaatan Lagu Anak-Anak Sebagai Media Pengembangan Karakter Pada Pendidikan Anak Usia Dini Di Paud Cahaya Hati Kabupaten Solok Selatan. Imaji, 18(2), 30037. https:// doi.org/10.21831/imaji.v18i2.30037

Ayuni, D., \& Setiawati, F. A. (2019). "Kebun Buah" Learning Media for Early Childhood Counting Ability Despa. Jurnal Obsesi : Jurnal Pendidikan Anak Usia Dini, 3(1), 1-9.

Basma, A. M. F., \& Melga, B. (2020). Perancangan Media Pembelajaran Mengenai Edukasi Pendidikan Karakter Melalui Lagu Anak Indonesia di Kota Bandung. E-Proceeding

Hasanah, U. (2018). Implementasi Pendidikan Multikultural dalam Membentuk Karakter Anak Usia Dini. Golden Age: Jurnal Pendidikan Anak Usia Dini, 2(1), 35-53. https:// doi.org/10.29313/ga.v2i1.3990

Indriana, U. A., Ismiyanti, Y., \& Afandi, M. (2019). Analisis Nilai Karakter Ppk Pada Lagu Anak-Anak Dalam Buku Tematik Terpadu Kurikulum 2013 Tema 4 Kewajiban Dan Hak Serta Penerapannya Di Sdn Genuksari 02. Prosiding Konferensi Ilmiah Mahasiswa Unissula, 2, 418-486.

Kusumawati, H. (2015). Pendidikan Karakter Melalui Lagu Anak-Anak. Imaji, 11(2), 283. https:// doi.org/10.21831/imaji.v11i2.3839

Laali, S. A. (2018). Pembentukan Karakter Anak Melalui Lagu Kokonua. Jurnal Pendidikan Islam Al-Ilmi, 1(2), 1-12. https:// doi.org/10.32529/al-ilmi.v1i2.250

Mahmudi, M., Listyarini, I., \& Untari, M. F. A. (2020). Analisis Nilai Karakter dalam Lagu Anak Karya A.T. Mahmud. DWIJALOKA Jurnal Pendidikan Dasar Dan Menengah, 1(2). https:// doi.org/10.35473/dwijaloka.v1i2.589

Miles, M., \& Huberman, M. (2005). No Qualitative Data Analysis (Terjemah). UI Press.

Muliati, B., \& Sari, R. (2018). Menanamkan Karakter Bangsa Melalui Lagu-Lagu Patriotik Bagi Peserta Didik Tingkat Pendidikan Dasar. Al-Hikmah: Jurnal Kependidikan Dan Syariah, 6(1), 1-11.

Mustopo, M. H. (1989). Manusia dan Budaya (Kumpulan essay Ilmu Budaya Dasar). Usaha Nasional.

Prahesti, S. I., Taulany, H., \& Dewi, N. K. (2019). Gerak dan Lagu Neurokinestetik (GELATIK) untuk Menumbuhkan Kreativitas Seni Anak Usia Dini. Jurnal Obsesi: Jurnal Pendidikan Anak Usia Dini, 4(1), 162. https://doi.org/10.31004/obsesi.v4i1.289

Purnomo, A., Hartono, R., Hartatik, H., Riasti, B. K., \& Hidayah, I. N. (2016). Pengembangan Aplikasi Info Lagu Nusantara Berbasis Android Untuk Melestarikan Warisan Budaya Indonesia. Simetris: Jurnal Teknik Mesin, Elektro Dan Ilmu Komputer, 7(2), 527. https:// doi.org/10.24176/simet.v7i2.764

Purwanto, S. (2019). Penanaman Nilai Karakter pada Anak Usia Dini melalui Pembelajaran Berbasis Musik dan Lagu Model. ThufuLA: Jurnal Inovasi Pendidikan Guru Raudhatul Athfal, 3(1), 1. https://doi.org/10.21043/thufula.v3i1.4663

Putra, M. E. H., \& Noordiana. (2020). Membangun Karakter Siswa Melalui Lagu "Si Semut" Karya Pambuko di SMPN 2 Mojo Kabupaten Kediri. Jurnal Pendidikan Sendratasik, 6(11), 951-952.

Rantina, M., Hasmalena, H., \& Yosef, Y. (2019). Pengembangan Lagu Berbasis Aplikasi Musescore dalam Pengembangan Aspek Perkembangan Anak Usia Dini. Jurnal Obsesi : Jurnal Pendidikan Anak Usia Dini, 4(1), 438. https://doi.org/10.31004/obsesi.v4i1.351 
Restian, A., \& Mukhlishina, I. (2017). Analisis Kesalahan Konsep Lagu Anak-Anak Pada Pendidikan Karakter Buku Guru Kelas 1-6 Di Sd. Prosiding Seminar Nasional Lembaga Kebudayaan (SENASGABUD), 1(71), 19-26. http://researchreport.umm.ac.id/index.php/SENASGABUD/article/view/1696/1911

Rosmiati, A. (2014). Teknik Stimulasi dalam Pendidikan Karakter Anak Usia Dini melalui Lirik Lagu Dolanan. Resital: Jurnal Seni Pertunjukan, 15(1), 71-82. https:// doi.org/10.24821/resital.v15i1.801

Rukiyati Sugiyo, \& L. Andriani Purwastuti. (2017). Local Wisdom-Based Character Education Model in Elementary School in Bantul Yogyakarta Indonesia. Sino-US English Teaching, 14(5), 130-142. https:// doi.org/10.17265/1539-8072/2017.05.003

Seriadi, S. L. N. (2019). Pembentukan Karakter Unggul Dan Nasionalis Pada Anak Usia Dini Melalui Sekar Rare. Pratama Widya : Jurnal Pendidikan Anak Usia Dini, 3(1), 31-38. https://doi.org/10.25078/pw.v3i1.709

Sholeh, T. A. (2018). Membangun Karakter Anak Usia Dini Melalui Lagu Islami Bella Tamara 1. Seminar Nasional Dan Call for Paper "Membangun Sinergitas Keluarga Dan Sekolah Menuju PAUD Berkualitas, 1, 193-196.

Tarmizi, M. (2017). Evaluasi Efektivitas Pendidikan Karakter Cinta Tanah Air Melalui Lagu Anak-Anak Evaluasi Afektivitas Pendidikan Karakter Cinta Tanah Air Melalui Lagu Anak-Anak Di Mis Al-Hidayah. Jurnal Pendidikan Dan Pembelajaran, 6(10).

Widjanarko, P. (2019). Penanaman Karakter Melalui Lagu-Lagu Nasional Di Paud Pelita Harapan Bangsa Kota Tegal. PAUDIA : Jurnal Penelitian Dalam Bidang Pendidikan Anak Usia Dini, 8(2), 95-101. https:// doi.org/10.26877/paudia.v8i2.4873

Wijiasih, F. E., Fajriyah, K., \& Sukamto. (2020). Penanaman Nilai Karakter Melalui Lagu Dolanan Anak dalam Pembelajaran Daring di SD Negeri 01 Mejagong. Jurnal Inovasi Pembelajaran Di Sekolah, 1(1), 59-66.

Zulaikhah, S. (2019). Penguatan Pendidikan Karakter Melalui Pendidikan Agama Islam Di Smpn 3 Bandar Lampung. Al-Tadzkiyyah: Jurnal Pendidikan Islam, 10(1), 83-93. https://doi.org/10.24042/atjpi.v10i1.3558 